\title{
Reducing the Use of Antimicrobials as a Solution to the Challenge of Antimicrobial Resistance (AMR): Approaching an Ethical Dilemma through the Lens of Planetary Health
}

\author{
Samuel O. Abimbola ${ }^{1, *} \mathbb{C}$, Melvine Anyango Otieno ${ }^{2}\left(\mathbb{D}\right.$ and Jennifer Cole ${ }^{3} \mathbb{C}$ \\ 1 Cyprus International Institute of Environmental and Public Health, Cyprus University of Technology, \\ Limassol 3036, Cyprus \\ 2 Department of Environmental Biology and Health, University of Eldoret, Eldoret 30100, Kenya; \\ melvineanyango@gmail.com \\ 3 Department of Geography, Royal Holloway, University of London, Egham TW20 0EX, UK; \\ Jennifer.cole@rhul.ac.uk \\ * Correspondence: sa.abimbola@edu.cut.ac.cy; Tel.: +357-9616-9566
}

Citation: Abimbola, S.O.; Otieno, M.A.; Cole, J. Reducing the Use of Antimicrobials as a Solution to the Challenge of Antimicrobial Resistance (AMR): Approaching an Ethical Dilemma through the Lens of Planetary Health. Challenges 2021, 12, 23. https://doi.org/10.3390/ challe12020023

Academic Editors: Susan L. Prescott, Ganesa R. Wegienka, Nicole Redvers and Jake Robinson

Received: 4 August 2021

Accepted: 10 September 2021

Published: 13 September 2021

Publisher's Note: MDPI stays neutral with regard to jurisdictional claims in published maps and institutional affiliations.

Copyright: (c) 2021 by the authors. Licensee MDPI, Basel, Switzerland. This article is an open access article distributed under the terms and conditions of the Creative Commons Attribution (CC BY) license (https:/ / creativecommons.org/licenses/by/ $4.0 /)$.

\begin{abstract}
Antimicrobial resistance (AMR) is one of the greatest challenges facing humanity in the 21st century. Controlled dispensation of antimicrobial drugs is the most echoed solution among many that have been postulated to counter this problem. However, the life-impacting significance of antimicrobials makes this approach a very complex one, which must be considered under the lens of health and planetary ethics. As the problem of AMR is not peculiar to only a few people, the right to know the risk, as well as decisions as to when and how antimicrobials are used should, not be granted to only a few decision makers, but be used as drivers to advance planetary health knowledge in a way that benefits individuals, society, and future generations. Within an ethical framework, implementing policies that extend the efficacy period of antimicrobials should be considered in a way that balances range, choice, and quality of drugs against stewardship activities. The challenge of AMR cannot be eliminated completely by reduced use of antimicrobials only; understanding how, where and when reduction is necessary, and social structures and patterns (as well as existing health and government systems) are required if any global/national intervention would be successful and equitable. We may well have gone past the stage of adopting precautionary principles as the danger we face presents no iota of uncertainty. The measures to control AMR's emergence and its spread are well presented. Nevertheless, we must not ere from the path of justice and equity even in the face of certain danger.
\end{abstract}

Keywords: antimicrobial resistance (AMR); ethics; planetary health; distributive justice; antimicrobial stewardship

\section{Introduction}

Ethical behaviour is the aggregation of actions, bound by a systematic code of actions and principles, which benefits both humans and the environment. Anything that poses a risk to the continued existence of humankind or any component of the environment must be considered in the light of an ethical code, especially when there is a moral implication of action and/or inaction. The increasing dangers associated with the emergence of antimicrobial resistance (AMR) places ethical obligations on those able to act, as failure to rise up effectively and efficiently to deal with this challenge will have grave consequences that will impact everyone. The final report of the 2014-2016 Review on Antimicrobial Resistance, chaired by Jim O'Neill [1] stated, “Antimicrobial drugs are medicines that are active against a range of infections, such as those caused by bacteria (antibiotics), viruses (antivirals), fungi (antifungals) and parasites (including antimalarials). Resistance of these microorganisms against medicines that have hitherto been active against the infections 
they cause, such that they can survive exposure to the medicine, is what is referred to as antimicrobial resistance (AMR)". While AMR could be intrinsic or acquired, the rate at which resistance is developed is a function of the actions (or inactions) of man (sic). If we vacillate much longer where there is need for action, we may soon find ourselves beyond the scope of possible redemption, a return, back to the pre-antibiotic era. Loss of drug potency would see us wave goodbye to all the life-saving benefits we enjoyed in the last 100 years and plunge us into a post-antimicrobial era, an era of untreatable infections as it were before the discovery of antibiotics.

This presents a complex, challenging ethical dilemma with no easy solution as antibiotics have become infrastructural not only to healthcare systems and to human life in general [2] but also to the livestock and agricultural systems on which many depend for adequate nutrition [3]. Antibiotic resistance presents a classic case study of an Anthropocene 'wicked problem' (a problem which has many independent factors which makes it very difficult or near impossible to solve) [4] that speaks to the need for a strong ethical code, which reaches beyond abstract principles to support and drive action. As such, scholars, and policymakers alike may benefit from approaching it through the lens of planetary health - the health of human civilisation and the state of the natural systems on which it depends [5], which is intrinsically aware of the need to weigh costs and benefits of potential actions in an increasingly resource-constrained world. In 2019, Foster et al. [6] prosed an ethical code for the field of planetary health which drew on the 2018 Canmore Declaration: Statement of Principles for Planetary Health [7] and the 1986 Ottawa Charter for Health Promotion [8]. A subsequent development of the original code [9] presents five key ethics identified as integral to planetary health: intergenerational responsibility; the right to know [the risks associated with (in)action]; the importance of distributive justice; the need to extend rights to the more-than-human-world; and the precautionary principle. This paper will address antimicrobial resistance through each of these ethics to highlight why and how it can best be approached in future to ensure the continued flourishing of not only humankind, but of all life on Earth.

Perhaps the most wicked ethical challenge posed by antibiotic resistance is the timescale on which antibiotics' efficacy slip away, making the challenge a 'rising tide' [10] rather than a systematic shock and thus harder to address: human psychology is wired to act on what is more immediate than on a vague, distant future [11]. Yet the need for intergeneration responsibility is as old as penicillin, an antibiotic drug developed by Alexander Fleming in 1928 [12]. Fleming both anticipated and warned about the dangers of AMR during his Nobel Lecture in 1945: the first evidence of resistance had been recorded three years earlier [13]. Fleming forewarned the danger of resistance due to the misuse of antibiotics through a story:

"I would like to sound one note of warning. Penicillin is to all intents and purposes non-poisonous so there is no need to worry about giving an overdose and poisoning the patient. There may be a danger, though, in under dosage. It is not difficult to make microbes resistant to penicillin in the laboratory by exposing them to concentrations not sufficient to kill them, and the same thing has occasionally happened in the body. The time may come when penicillin can be bought by anyone in the shops. Then there is the danger that the ignorant man may easily under dose himself and by exposing his microbes to non-lethal quantities of the drug make them resistant. Here is a hypothetical illustration. Mr. X. has a sore throat. He buys some penicillin and gives himself, not enough to kill the streptococci but enough to educate them to resist penicillin. He then infects his wife. Mrs. X gets pneumonia and is treated with penicillin. As the streptococci are now resistant to penicillin the treatment fails. Mrs. $X$ dies. Who is primarily responsible for Mrs. X's death? Why Mr. X whose negligent use of penicillin changed the nature of the microbe. There is a moral here, and that is that if you use penicillin, use enough" (Fleming, 1945) [14].

Eight decades after, the projections of Fleming have become our reality. We are saddled with the responsibility of finding a solution to a problem that was created from our abuse 
of a solution to a previous problem. In order to achieve this goal, we must understand that microbes are as much an essential component of living organisms (symbiotic microbes) as they are pathogenic (parasitic microbes), making them an unerasable part of the planetary system. Thus, it is not entirely a problem of finding a way to eliminate microbes but one of finding a way to cohabit with them in a symbiotic way, while giving no room for pathogens to proliferate or mutate. Future initiatives must consider this bifocal relationship between man and microbes. We must also consider the many other anthropogenic factors such as social structures, knowledge and the behavioural patterns of target populations, justice (to both the present generation and the ones unborn), equitable distribution of resources and the rights of all other components of our environment.

\section{The Right to Know [the Risks]}

Fleming recognized the moral imperative inherent in antibiotic utilization. He acted ethically by making clear the risks, and thus providing the knowledge needed to act. He considered the needs of future generations; to continue to ignore his prophetic warning, as humankind has done for nearly three-quarters of a century, is deeply unethical. While it is arguable that his message clearly only emphasized the dangers of underusing antibiotics (penicillin), it can also be inferred that humankind was forewarned of the consequences of misusing (over or underusing) penicillin and, by extension, all antimicrobials. Antimicrobial agents are unique in this regard: they are the only pharmaceutical drugs whose loss of efficacy over time is transmissible [15]. In essence, not only can the microbes develop resistance themselves, they can transfer that resistance to other microbial agents through horizontal gene transfer [16], enabling resistance that emerges anywhere to spread across the globe. The world is fast approaching a time whereby people may die from previously treatable infections due to a loss of drug effectiveness [17]. According to statistics by the World Health Organization [18], an estimated 700,000-1,000,000 people already die yearly from AMR-related illnesses with an estimated global economic cost of more than one hundred billion British Pounds $(£ 100,000,000,000)$. They have also predicted as many as 10 million lives could be lost annually to AMR by 2050, with an economic cost of approximately 66 trillion British Pounds $(£ 66,000,000,000,000)$ if it is not tackled. The gravity of the challenge is staring us in the face: the risk is clear.

Considered in the context of the triad of imagination challenges, knowledge challenges and implementation challenges facing the field of planetary health [5], it is safe to say that we need to address AMR from a perspective that goes beyond morally obliging individuals to use antimicrobials responsibly: human beings do not always act morally even when the risks of not doing so are known. The arguments supporting the right to know have been premised upon the supposition that an increase in knowledge can often translate to a change in behaviour. Without doubt, there is the need for an increase in the level of awareness of populations of the dangers of AMR and how to control this: a number of researchers [19-21] all agree that knowledge plays a role in how farmers, patients and/or prescribers use antimicrobials. As such, they conclude that there is need for an increase in research as well as to increase awareness of interventions in LMICs in order to address AMR. While this is a possibility, social scientists have shown that human behaviour is often independent of the level of knowledge. Studies [22-24] show that an increase in knowledge do not always translate to a change in behaviour as is often expected.

What then? Is there a need for increased awareness, especially in regions where there is a knowledge and/or research deficit, or not? Of course there is, but not by itself alone. The right to know must be extended beyond education only. There is a need to understand the social structures of the target populations-social determinants of health, the existing practices and their deficiencies, if any, available health systems and governmental policies, and any other important dynamics necessary to developing a holistic solution. We need to initiate policies that will extensively mitigate the challenge of AMR and extend the duration of viability of antimicrobials but we need to do this ethically, ensuring that policies impact all countries equitably: those who currently use too many antibiotics and those who 
still do not have enough. The right to know needs to be used as a rally cry, a reminder that planetary health must not be just an academic field but also a movement and a call to action [25]. AMR is a worrisome challenge but its gravity must not cause us to shy away from prospective action plans and policies that build on planetary health's ethical framework to give a balanced perception of the associated risks of AMR and benefits of controlling it. How much risk is acceptable? Are the benefits and risks equally shared by all? What/who are the opportunity costs? Must we conserve the efficacy of antimicrobials for future use if this can only be done at the expense of some of today's patients? These questions bring us to the second ethic to be considered: that of distributive justice.

\section{Distributive Justice: Beneficence and the Common Good}

There are no 'all benefits, no risks' solution(s) to the challenge of AMR, just as there are none to many of the public and planetary health challenges we face, such as climate change [26]. The best we can hope for is a 'least-risk' solution that unbiasedly benefits (or not) everyone equally, wherever they are on Earth or in time. This needs to be examined through two lenses that help to illuminate the challenge of AMR: bioethical principles and distributive justice.

Almost every solution proposed by different persons and bodies to the challenge of AMR has suggested either a reduction in the use of antimicrobials [27-29] and/or increasing research into the development of new (novel) antimicrobials [30,31]. The former would help to stem the tide of the AMR emergence, while the latter would put humanity at a positional advantage against AMR, both in the present and the future. However, this twin proposal creates a cascade of intertwined ethical dilemmas and problems: a reduction in the use of antimicrobials may result in reduced revenue generation for pharma companies, causing the unexpected effect of reduction in R\&D of new antimicrobials by the companies as the economic incentive to do so is lost. As such it becomes difficult to achieve the twin benefits of reduction in use of existing antimicrobials and increase in research for new antimicrobials.

There is also the problem of equal distribution of antimicrobials globally. While some countries are faced with the challenge of stemming the tide of excessive use of antimicrobials, others-and in particular, low-and-middle-income countries (LMICs)—do not have access to all the antimicrobials they may need for adequate healthcare of people and livestock. As was observed by Jonas et al. [32], "the health and economic consequences of AMR are known to affect poorer countries disproportionately ..." . This has proliferated the introduction of counterfeit, less effective medicines into such countries to bridge the demand gap, a situation that is only likely to increase if access to legitimate antibiotics is more tightly but irrationally controlled [33]. Addressing this problem is therefore of utmost importance. It is however also important to mention that the dilemma of AMR in LMICs is not solely a problem of distribution; there are several other contributory factors such as the lack of prescription tracking systems at both national and subnational levels, paucity of appropriate knowledge of the impact of misuse or abuse (overdose and/or underdose) of antibiotics on ecosystems among farmers, farmers relying more on the advice of their peers than those of agrovets or animal health workers when treating their animals, low level of knowledge of antimicrobial stewardship strategies among major stakeholders (veterinarians, agrovets, community animal health workers, students, paraprofessionals, farmers, pharmacist, feed distributors, government regulatory agencies, etc.), and the ease of farmers' access to antibiotics including those crucial for human health $[19,20]$. Furthermore, poor quality and availability of healthcare systems, poor governmental control over drug distribution and sale which allows for over-the-counter procurement even without prescription, patients' use of antimicrobials without the supervision of certified healthcare workers, competition between pharma companies as a result of profit consciousness, bureaucratic process and so on $[19,21]$. All these exacerbate the problem of AMR in LMICs. It has also increased over-the-internet and black-market demand for authentic drugs, compromising international control [34]. Therefore, any and all proposed 
policies and decisions to be discussed or implemented must consider how easy it will be for low- and middle-income countries to access genuine medicines and treatment, as well as factor in the need for antimicrobial stewardship training programmes for all stakeholders across all levels in order to control the development of AMR.

Successfully implementing a reduction in use of antibiotics with the least risks possible would serve the common good of everyone. The continued sustenance of life on Earth may well hinge upon, among other necessities, humankind's ability to suppress AMR. Without antibiotics, unless effective alternative(s) are developed, certain medical procedures such as organ transplants and major surgery may well become too risky [35], and even unethical to attempt. But if we are to reduce the use of antibiotics when an estimated 5.7 million people around the world already die annually from antibiotic-treatable infections due to lack of access to effective drugs [36], who should decide who will receive treatment if access to them is to be restricted further?

There are undoubtedly economic benefits to be gained if the WHO-predicted $£ 66$ trillion economic cost of AMR by 2050 can be avoided, even if not in its entirety. Investment is needed to fund research into alternatives, such as better welfare conditions for livestock raised in overcrowded, unsanitary conditions that create situations in which bacteria thrive and disease can easily spread [37]. Investment in vaccination delivery, as well as development [38] could benefit low- and middle-income countries (LMIC) by providing access to medical and financial resources. Potential solutions need to be more context appropriate, affordable and practical in low-resource settings [39], designed to not overload already stretched human and animal healthcare systems in the event that infectious disease cannot be entirely eliminated. If achieved, the healthcare of humans and livestock would be greatly improved. The benefits are immense but there are certain shortcomings that stand to be overlooked if we only gaze upon the supposed benefits.

Proposed solutions must remain mindful of autonomy, justice and equity, which must be afforded to all of humanity. Autonomy dictates that the rights of every human being must be preserved, not abused. Actions that directly or indirectly affect the life or standard of living of a person(s), whether positively or otherwise, must not be carried out without the consent of the affected person(s). Will everyone have equal power to decide the mode and guidelines employed in the implementation of a policy such as restricted antibiotic access, however? Could every patient be granted the right to choose or not to use antimicrobials, and how would it be decided if there is no risk, minimal risk or an acceptable level of risk to others from doing so? And acceptable to whom? What should be the role of doctors in reducing the prescription of antimicrobials to patients: advisory or mandatory, and how does this intersect with the Hippocratic Oath's "Do no harm"? Some scholars have argued that by prescribing antibiotics in the knowledge that doing so drives resistance, medical professionals do indeed do harm [40,41] but the Hippocratic Oath, and most decisions made in medical ethics, have traditionally had to consider harm only in relation to the individual and in the present, not to the global population or to theoretical future generations. The current approach ignores planetary health's strong ethical requirement not only for distributive justice in the present, but also for intergenerational responsibility.

\section{Intergenerational Responsibility}

There has been considerable focus in recent decades on the need for medical doctors and other health practitioners to cut down on the administration of antimicrobials, particularly in situations where they are not really necessary [42]. No matter how pressured doctors may be by patients or their carers, they, and society more widely, also have an ethical obligation to protect the best interest of others, including future generation(s). A proposal to reduce the use of antimicrobials in the treatment of presently at-risk patients, irrespective of the severity of their infection, creates room to argue that the right of the present-day patient to autonomy, and their right to be a part of the decision-making process in their treatment (or not) with antibiotics, is superseded and superimposed by the obligation to make sure future patients (even those with less severe infections) will still 
have access to antibiotics. However, future patients are as yet unborn and the structure and operation of future healthcare systems is also as yet unknown. Health practitioners have just as much ethical obligation to juxtapose the right of present patients against that of future patients so as to protect them from harm now, even if their immediate risk seems small.

Scholars disagree over whether people who do not yet exist should have rights. Some say not [43], whilst others counter that it is unethical not to act against something known to be storing up problems for the future [44] but who decides which usage (present or future) is more just? Dealing with AMR requires difficult decisions that threaten to impede people's freedom to access the health benefits of potentially life-saving antimicrobials, which may in turn challenge their right to information and take away the right to informed consent if patients are refused antibiotics which they would choose to take. Each patient will not equally bear the consequence(s) of using/not using antimicrobials, especially in therapeutic situations; so, should the patient alone, their healthcare providers or society more widely have a say in deciding their fate? And who should be empowered to make the deciding vote?

Focusing on those with the greatest need is also problematic. A patient may be informed they do not need antibiotic therapy after examination by a doctor but in many areas of the world, examination by a doctor remains a luxury that is out of reach; the sale of antibiotics only with a prescription denies many patients access to them at all [45]. The outcome of decisions to restrict and more strongly regulate use therefore has different direct/indirect effects depending on who the patient is and where they live. With this in mind, who should be able to define, and how, guidelines and rules of engagement that bound such situations without taking away the autonomy of the patient and/or give them reason to abide by a decision made for the greater good?

Can we justify reducing the use of antimicrobials in a bid to create a better future for generations yet to be born if such a decision means allowing some of the present generation to die prematurely, or to live with a fair amount of pain that a knee or hip operation could reduce, especially when this is considered in light of the fact that antibiotic resistance is inevitable. How much withholding is ethical? For whom? It is by now certain that everyone plays a role in the continued emergence and proliferation of AMR and as such everyone has a duty to do what they can to prevent it. However, practices such as the administration of prophylactic antimicrobials to healthy but 'at risk' patients are not easy to prohibit, especially where the opportunity cost for such actions could be more severe outcomes for those who are currently only moderately/severely infected. As Leibovic et al. [46] have noted, "Patients with moderate to severe infections are given less than maximum empirical antibiotic treatment in order to reduce the rise in resistance ..." ". This practice creates further challenges as it dangerously treads the edges of misuse (underuse) of antimicrobials, a practice complicit in creating the present situation. It also leaves behind it the question of how much less than maximum is just above an acceptable minimum, as well as the inevitable ethical challenges of who is deemed worthy, and who can afford to pay if they are given the chance. Collective decision making by all stakeholders would be a proper way to do this but that itself is unlikely to be free of ethical dilemmas.

\section{Extending Rights to the More-than-Human World}

Maintaining the efficacy of antimicrobials for future patients may depend on alternative solutions that do not drive resistance but use ameliorative therapeutic methods rather than possible curative ones, but these do not always effectively deal with the immediacy of the problem. Faced with an already identified at-risk patient with a severe infection, physicians have few options other than antibiotics. One longer-term option is to try harder to avoid infection in the first place. One can look to medical science (and in particular the pipeline of new drugs) as the answer [47], but another option is to give more consideration to why bacteria resist. Developing a deeper understanding of the power relationship between humans and microbes, informed by our understanding of colonial and post-colonial 
history, can forge new relationships between us [48] and, most importantly, encourage us not to antagonise microbes further. To do this, we need to consider the place of antibiotics in the more-than-human world.

AMR has always developed in nature, even before the discovery of the Penicillin by Fleming: traces of it have been found in ancient permafrost, isolated caves and centuries old mummies [49]. Microorganisms have always and will always develop resistance against any agent that is biocidal to them and will constantly evolve and proliferate even in extreme conditions. Microbes, and alongside it, AMR, are ubiquitous in the environment [50], found in water [51], soil [52,53], farms [54] and industrial cities [55]. It is therefore safe to say that reducing the use of antimicrobials in humans would not stop microorganisms from developing resistance nonetheless.

A few other ethical considerations involving the more-than-human world stare us in the face. The present rate at which antimicrobials are used in agriculture and veterinary medicine poses just as great a challenge of increasing AMR, if not greater, than that posed by their use in human medicine [56,57]. As such, structural and systemic control of the use of antibiotics/antimicrobials in agriculture and aquaculture [58] would be important in managing the rise in AMR. However, indiscriminately placing restrictions on the use of antimicrobials in veterinary medicine, agriculture and aquaculture without considering the social constructs of the people or environment in which it is placed may not solve the problem either, however [59], but rather threaten the quality and quantity of animal health productions available. The resultant economic-as well as ethicalconsequences of such policies to further limit antibiotic use in livestock and fisheries will be immense [60]. Moreover, as earlier posited, efforts to develop new antibiotics could ironically be undermined by the drive to reduce their overall use. R \& D companies will be even more reluctant to develop new classes of antibiotics if they not only promise short-term returns at best, but their use is being actively discouraged. Nevertheless, none of these concerns detract from the fact that controlling antibiotic prescription and usage in agriculture is paramount to controlling AMR.

The successful transition to a post-antibiotic world may therefore be dependent on bioindustries, or governments, shoring up research into alternative non-antimicrobial solutions to disease risk such as organic acids [61], phytogenic products [62] or bacteriophages [63]. Non-pharmaceutical mechanisms to maintain or even increase agricultural production, such as improved hygiene [64,65] could also be used instead of, or alongside, use reduction policies, and may be possible to implement with less risk to farming systems and the people who depend on them for food.

We know the risks from antibiotic use, and the dangers inherent in it. Returning to the three imagination challenges set out in The Lancet commission [5], the imagination challenge (the existence of the risk and its consequences) is well understood. The knowledge challenge (quantifying, surveying, recording and modelling futures (with or without antibiotics)) has also been well met. This leaves only the implementation challenge, which may depend more on ethics than on science. We know what needs to be done, and broadly, how to do it, but we need to act, and act in a way that, bearing in mind everyone has the right to know the risk and its consequences, will ensure distributive justice and intergenerational responsibility whilst extending rights to the more-than-human world, including the environment and the animals and microbes who share it with us.

\section{Conclusions: Too Late for the Precautionary Principle}

There is one of the five key planetary health ethics missing from the discussion above: the precautionary principle. Long a mainstay of ethical discussions, the precautionary principle urges caution in the face of uncertainty. However, there is no uncertainty in the case of antimicrobial resistance. Antimicrobials are a unique, valuable but disproportionately distributed resource. They are of immense importance to humankind but their efficacy, and thus value, declines with use. The preservation of their effectiveness as a resource is currently posing a herculean task for which several policies and means of regulating have 
been proposed [66-69], none of which have so far proved entirely successful. The challenge from AMR is distinct from almost all other challenges humanity faces, however, and many of the solutions proposed so far have overlooked this uniqueness. The proposition of reducing the use and administration of antimicrobials, while increasing research and accounting for fair use of antimicrobials across and within generations, struggles against some aspects of distributive justice and the rights of the more-than-human environment and animal kingdoms.

The complexity of the challenge posed by AMR thus needs to be weighed within and against myriad practical and ethical problems than run through the policy solutions that could be employed to tackle it. Antimicrobial resistance will always develop in nature, even to drugs that are yet to be developed. A greater solution would be the innovation of therapies that do not encourage resistance. The question of if and when it is ethical to withhold antibiotics if doing so constitutes a risk to patients remains open and must be answered not only with some urgency, but also transparently, particularly if some patients are to be lost in the present to protect those of the future. The patient's right to autonomy and justice must not be overlooked.

As with every other ethical dilemma, the challenge of AMR will only be addressed effectively in policy development and debates through a holistic approach that factors in every stakeholder including patients, pharmaceuticals developers, clinicians and physicians, veterinarians and the livestock industry, bio-industries, policy-makers—and many others. One thing however is sure: our future health depends on forming an international framework that resolves-or at least substantially reduces-the problem of AMR. We need to keep ethics in the foreground of all discussions, though the framework itself is likely to be built around political, economic, social, technological, legal and environmental instruments [70] and needs to acknowledge that irrespective of how many preventive measures are put in place, infections and the microbes that cause them will never be entirely eradicated. As long as there are bacteria, we will always be at the mercy of AMR and in need of new, effective therapeutic solutions to this problem, including alternative solution(s) that do not drive resistance. Learning to share a more-than-human world with bacteria may prove a better long-term solution than focusing on approaches that only grant us, at best, the benefit of extra time.

Author Contributions: Conceptualization, S.O.A., J.C. and M.A.O.; methodology, S.O.A., M.A.O. and J.C.; resources, S.O.A., M.A.O. and J.C.; data curation, S.O.A., M.A.O. and J.C.; writing-original draft preparation, S.O.A. and J.C.; writing-review and editing, S.O.A., M.A.O. and J.C.; visualization, S.O.A. and M.A.O.; supervision, J.C. All authors have read and agreed to the published version of the manuscript.

Funding: Authors have received no funding.

Institutional Review Board Statement: Not applicable.

Informed Consent Statement: Not applicable.

Data Availability Statement: Not applicable.

Conflicts of Interest: The authors declare no conflict of interest.

\section{References}

1. O'Neill, J. The Review on Antimicrobial Resistance. Tackling Drug-Resistant Infections Globally: Final Report and Recommendations. 2016. Available online: https://amr-review.org/sites/default/files/160525_Final\%20paper_with\%20cover.pdf/ (accessed on 18 November 2020).

2. Chandler, C.I. Current accounts of antimicrobial resistance: Stabilisation, individualisation and antibiotics as infrastructure. Palgrave Commun. 2019, 5, 1-13. [CrossRef]

3. Skandalis, N.; Maeusli, M.; Papafotis, D.; Miller, S.; Lee, B.; Theologidis, I.; Luna, B. Environmental spread of antibiotic resistance. Antibiotics 2021, 10, 640. [CrossRef]

4. Littmann, J.; Simonsen, G.S. Antimicrobial resistance is a super wicked problem. Tidsskr. Den Nor. Legeforening 2019, 139, 10. [CrossRef] 
5. Whitmee, S.; Haines, A.; Beyrer, C.; Boltz, F.; Capon, A.; Dias, B.F.D.S.; Ezeh, A.; Frumkin, H.; Gong, P.; Head, P.; et al. Safeguarding human health in the Anthropocene epoch: Report of The Rockefeller Foundation-Lancet Commission on planetary health. Lancet 2015, 386, 1973-2028. [CrossRef]

6. Foster, A.; Cole, J.; Farlow, A.; Petrikova, I. Planetary health ethics: Beyond first principles. Challenges 2019, 10, 14. [CrossRef]

7. Prescott, S.L.; Logan, A.C.; Albrecht, G.; Campbell, D.E.; Crane, J.; Cunsolo, A.; Holloway, J.W.; Kozyrskyj, A.L.; Lowry, C.A.; Penders, J.; et al. The canmore declaration: Statement of principles for planetary health. Challenges 2018, 9, 31. [CrossRef]

8. World Health Organization; Canadian Public Health Association. Ottawa Charter for Health Promotion; Bulletin of the Pan American Health Organization (PAHO): Washington, DC, USA, 1987; Volume 21, pp. 200-204.

9. Foster, A.; Cole, J.; Farlow, A.; Petrikova, I.; Frumkin, H. Planetary Health: Protecting Nature to Protect Ourselves; Myers, S., Frumkin, H., Eds.; Island Press: Washington, DC, USA, 2020.

10. Cole, J. Antimicrobial resistance-A 'rising tide' of national (and international) risk. J. Hosp. Infect. 2016, 92, 3-4. [CrossRef] [PubMed]

11. Allen, S. Future-Mindedness; Greater Good Science Center (GGSC) at UC Berkeley: Berkeley, CA, USA, 2019.

12. Ligon, B.L. Penicillin: Its discovery and early development. In Seminars in Pediatric Infectious Diseases; WB Saunders: Philadelphia, PA, USA, 2004; Volume 15, pp. 52-57.

13. Abraham, E.P.; Chain, E. An enzyme from bacteria able to destroy penicillin. Nature 1940, 146, 837. [CrossRef]

14. Fleming, A. Nobel lecture-Penicillin. In Nobel Lectures, Physiology or Medicine 1942-1962; Elsevier Publishing Company: Amsterdam, The Netherlands, 1964; pp. 83-93.

15. Spellberg, B.; Srinivasan, A.; Chambers, H.F. New Societal Approaches to Empowering Antibiotic Stewardship. JAMA 2016, 315, 1229-1230. [CrossRef] [PubMed]

16. Sun, D.; Jeannot, K.; Xiao, Y.; Knapp, C.W. Editorial: Horizontal gene transfer mediated bacterial antibiotic resistance. Front. Microbiol. 2019, 10, 1933. [CrossRef]

17. Gallagher, J. Analysis: Antibiotic Apocalypse. BBC News Online. Available online: http://www.bbc.co.uk/news/health-217026 47 (accessed on 30 November 2020).

18. World Health Organization. Antimicrobial Resistance: Draft Global Action Plan on Antimicrobial Resistance (Report by the Secretariat); World Health Organization: Geneva, Switzerland, 2014. Available online: https://apps.who.int/gb/ebwha/pdf_files/EB136/B1 36_20-en.pdf/ (accessed on 18 November 2020).

19. Phares, C.A.; Danquah, A.; Atiah, K.; Agyei, F.K.; Michael, O.-T. Antibiotics utilization and farmers' knowledge of its effects on soil ecosystem in the coastal drylands of Ghana. PLoS ONE 2020, 15, e0228777. [CrossRef] [PubMed]

20. Afakye, K.; Kiambi, S.; Koka, E.; Kabali, E.; Dorado-Garcia, A.; Amoah, A.; Kimani, T.; Adjei, B.; Caudell, M.A. The impacts of animal health service providers on antimicrobial use attitudes and practices: An examination of poultry layer farmers in ghana and kenya. Antibiotics 2020, 9, 554. [CrossRef] [PubMed]

21. Wilkinson, A.; Ebata, A.; MacGregor, H. Interventions to reduce antibiotic prescribing in LMICs: A scoping review of evidence from human and animal health systems. Antibiotics 2018, 8, 2. [CrossRef] [PubMed]

22. Haenssgen, M.J.; Charoenboon, N.; Zanello, G.; Mayxay, M.; Reed-Tsochas, F.; Lubell, Y.; Wertheim, H.; Lienert, J.; Xayavong, T.; Zaw, Y.K.; et al. Antibiotic knowledge, attitudes and practices: New insights from cross-sectional rural health behaviour surveys in low-income and middle-income South-East Asia. BMJ Open 2019, 9, e028224. [CrossRef] [PubMed]

23. Lambert, H.; Chen, M.; Cabral, C. Antimicrobial resistance, inflammatory responses: A comparative analysis of pathogenicities, knowledge hybrids and the semantics of antibiotic use. Palgrave Commun. 2019, 5, 85. [CrossRef]

24. Charani, E.; Smith, I.; Skodvin, B.; Perozziello, A.; Lucet, J.-C.; Lescure, F.-X.; Birgand, G.; Poda, A.; Ahmad, R.; Singh, S.; et al. Investigating the cultural and contextual determinants of antimicrobial stewardship programmes across low-, middle- and high-income countries-A qualitative study. PLoS ONE 2019, 14, e0209847. [CrossRef]

25. Horton, R.; Beaglehole, R.; Bonita, R.; Raeburn, J.; McKee, M.; Wall, S. From public to planetary health: A manifesto. Lancet 2014, 383, 847. [CrossRef]

26. Cole, J.; Dodds, K. Unhealthy geopolitics: Can the response to COVID-19 reform climate change policy? Bull. World Health Organ. 2020, 99, 148-154. [CrossRef]

27. Viens, A.M.; Littmann, J. Is antimicrobial resistance a slowly emerging disaster? Public Health Ethics 2015, 8, 255-265. [CrossRef]

28. Maillard, J.-Y.; Bloomfield, S.F.; Courvalin, P.; Essack, S.Y.; Gandra, S.; Gerba, C.P.; Rubino, J.R.; Scott, E.A. Reducing antibiotic prescribing and addressing the global problem of antibiotic resistance by targeted hygiene in the home and everyday life settings: A position paper. Am. J. Infect. Control. 2020, 48, 1090-1099. [CrossRef]

29. Llor, C.; Bjerrum, L. Antimicrobial resistance: Risk associated with antibiotic overuse and initiatives to reduce the problem. Ther. Adv. Drug Saf. 2014, 5, 229-241. [CrossRef] [PubMed]

30. Annunziato, G. Strategies to overcome antimicrobial resistance (AMR) making use of non-essential target inhibitors: A review. Int. J. Mol. Sci. 2019, 20, 5844. [CrossRef]

31. González-Bello, C. Antibiotic adjuvants-A strategy to unlock bacterial resistance to antibiotics. Bioorg. Med. Chem. Lett. 2017, 27, 4221-4228. [CrossRef] [PubMed]

32. Jonas, O.B.; Irwin, A.; Berthe, F.; Cesar, J.; Le Gall, F.G.; Marquez, P.V. Drug-Resistant Infections: A Threat to Our Economic Future (Vol. 2): Final Report; HNP/Agriculture Global Antimicrobial Resistance Initiative; World Bank Group: Washington, DC, USA, 2017. 
33. Sulis, G.; Gandra, S. Access to antibiotics: Not a problem in some LMICs. Lancet Glob. Health 2021, 9, e561-e562. [CrossRef]

34. Parsonage, B. Control of Antimicrobial Resistance Requires an Ethical Approach. Front. Microbiol. 2017, 8, 21-24. [CrossRef]

35. Fox, R. The post-antibiotic era beckons. J. R. Soc. Med. 1996, 89, 602. [CrossRef]

36. Daulaire, N.; Bang, A.; Tomson, G.; Kalyango, J.N.; Cars, O. Universal access to effective antibiotics is essential for tackling antibiotic resistance. J. Law Med. Ethic 2015, 43, 17-21. [CrossRef] [PubMed]

37. Hinchliffe, S.; Bingham, N.; Allen, J.; Carter, S. Pathological Lives: Disease, Space and Biopolitics; John Wiley \& Sons: Hoboken, NJ, USA, 2016.

38. Bloom, D.E.; Black, S.; Salisbury, D.; Rappuoli, R. Antimicrobial resistance and the role of vaccines. Proc. Natl. Acad. Sci. USA 2018, 115, 12868-12871. [CrossRef]

39. Cole, J.; Desphande, J. Poultry farming, climate change, and drivers of antimicrobial resistance in India. Lancet Planet. Health 2019, 3, e494-e495. [CrossRef]

40. Garau, J. Impact of antibiotic restrictions: The ethical perspective. Clin. Microbiol. Infect. 2006, 12, 16-24. [CrossRef]

41. Pirofski, L.-A. Why antibodies disobey the Hippocratic Oath and end up doing harm: A new clue. J. Clin. Investig. 2010, 120, 3099-3102. [CrossRef] [PubMed]

42. D'Atri, F.; Arthur, J.; Blix, H.S.; Hicks, L.A.; Plachouras, D.; Monnet, D.L. The European Survey on Transatlantic Task Force on Antimicrobial Resistance (TATFAR) action 1.2 group Targets for the reduction of antibiotic use in humans in the Transatlantic Taskforce on Antimicrobial Resistance (TATFAR) partner countries. Eurosurveillance 2019, 24, 1800339. [CrossRef]

43. Gaba, J.M. Environmental ethics and our moral relationship to future generations: Future rights and present virtue. Colum. J. Envtl. L 1999, 24, 249.

44. Gardiner, S.M. A perfect moral storm: Climate change, intergenerational ethics and the problem of moral corruption. Environ. Values 2006, 15, 397-413. [CrossRef]

45. Peltzman, S. By Prescription Only... or Occasionally. Regulation 1987, 11, 23.

46. Leibovici, L.; Paul, M.; Ezra, O. Ethical dilemmas in antibiotic treatment. J. Antimicrob. Chemother. 2011, 67, 12-16. [CrossRef] [PubMed]

47. Luepke, K.H.; Mohr III, J.F. The antibiotic pipeline: Reviving research and development and speeding drugs to market. Expert Rev. Anti-Infect. Ther. 2017, 15, 425-433. [CrossRef] [PubMed]

48. Hinchliffe, S. Postcolonial global health, post-colony microbes and antimicrobial resistance. Theory Cult. Soc. 2021, 1990, 95-96. [CrossRef]

49. Palma, E.; Tilocca, B.; Roncada, P. Antimicrobial resistance in veterinary medicine: An overview. Int. J. Mol. Sci. 2020, $21,1914$. [CrossRef]

50. Finley, R.L.; Collignon, P.; Larsson, D.J.; McEwen, S.A.; Li, X.-Z.; Gaze, W.H.; Reid-Smith, R.; Timinouni, M.; Graham, D.W.; Topp, E. The scourge of antibiotic resistance: The important role of the environment. Clin. Infect. Dis. 2013, 57, 704-710. [CrossRef]

51. Zhang, X.-X.; Zhang, T.; Fang, H.H.P. Antibiotic resistance genes in water environment. Appl. Microbiol. Biotechnol. 2009, 82, 397-414. [CrossRef]

52. Esiobu, N.; Armenta, L.; Ike, J. Antibiotic resistance in soil and water environments. Int. J. Environ. Health Res. 2002, 12, 133-144. [CrossRef] [PubMed]

53. Lee, J.H.; Park, K.S.; Jeon, J.H.; Lee, S.H. Antibiotic resistance in soil. Lancet Infect. Dis. 2018, 18, 1306-1307. [CrossRef]

54. Martinez, J.L. Environmental pollution by antibiotics and by antibiotic resistance determinants. Environ. Pollut. 2009, 157, 2893-2902. [CrossRef] [PubMed]

55. Yan, Z.-Z.; Chen, Q.-L.; Zhang, Y.J.; He, J.-Z.; Hu, H.-W. Antibiotic resistance in urban green spaces mirrors the pattern of industrial distribution. Environ. Int. 2019, 132, 105106. [CrossRef]

56. Schmidt, C.W. Antibiotic resistance in livestock: More at stake than steak. Environ. Health Perspect. 2002, 110, A396-A402. [CrossRef] [PubMed]

57. Zhu, D.; Giles, M.; Daniell, T.; Neilson, R.; Yang, X.R. Does reduced usage of antibiotics in livestock production mitigate the spread of antibiotic resistance in soil, earthworm guts, and the phyllosphere? Environ. Int. 2020, 136, 105359. [CrossRef]

58. Sivaraman, G.; Muneeb, K.; Sudha, S.; Shome, B.; Cole, J.; Holmes, M. Prevalence of virulent and biofilm forming ST88-IV-t2526 methicillin-resistant Staphylococcus aureus clones circulating in local retail fish markets in Assam, India. Food Control 2021, 127, 108098. [CrossRef]

59. Tiseo, K.; Huber, L.; Gilbert, M.; Robinson, T.P.; Van Boeckel, T.P. Global trends in antimicrobial use in food animals from 2017 to 2030. Antibiotics 2020, 9, 918. [CrossRef]

60. Chand, A. Economic implications of antimicrobial use policies. Nat. Food 2020, 1, 591. [CrossRef]

61. Dai, D.; Qiu, K.; Zhang, H.-J.; Wu, S.-G.; Han, Y.-M.; Wu, Y.-Y.; Qi, G.-H.; Wang, J. Organic acids as alternatives for antibiotic growth promoters alter the intestinal structure and microbiota and improve the growth performance in broilers. Front. Microbiol. 2021, 11, 618144. [CrossRef]

62. Bajagai, Y.S.; Alsemgeest, J.; Moore, R.J.; Van, T.T.H.; Stanley, D. Phytogenic products, used as alternatives to antibiotic growth promoters, modify the intestinal microbiota derived from a range of production systems: An in vitro model. Appl. Microbiol. Biotechnol. 2020, 104, 10631-10640. [CrossRef]

63. Wang, C.-H.; Hsieh, Y.-H.; Powers, Z.M.; Kao, C.-Y. Defeating antibiotic-resistant bacteria: Exploring alternative therapies for a post-antibiotic era. Int. J. Mol. Sci. 2020, 21, 1061. [CrossRef] 
64. Hu, Y.J.; Cowling, B.J. Reducing antibiotic use in livestock, China. Bull. World Health Organ. 2020, 98, 360. [CrossRef]

65. Ramay, B.M.; Caudell, M.A.; Cordón-Rosales, C.; Archila, L.D.; Palmer, G.H.; Jarquin, C.; Moreno, P.; McCracken, J.P.; Rosenkrantz, L.; Amram, O.; et al. Antibiotic use and hygiene interact to influence the distribution of antimicrobial-resistant bacteria in low-income communities in Guatemala. Sci. Rep. 2020, 10, 1-10. [CrossRef]

66. Howard, S.J.; Catchpole, M.; Watson, J.; Davies, S.C. Antibiotic resistance: Global response needed. Lancet Infect. Dis. 2013, 13, 1001-1003. [CrossRef]

67. Aguirre, E. An international model for antibiotics regulation. Food Drug Law J. 2017, 72, 295-313.

68. Edwards, S.E.; Morel, C.M.; Busse, R.; Harbarth, S. Combatting antibiotic resistance together: How can we enlist the help of industry? Antibiotics 2018, 7, 111. [CrossRef]

69. Storehagen, L.; Aftab, F.; Årdal, C.; Savic, M.; Røttingen, J.-A. Should antibiotics be controlled medicines? Lessons from the controlled drug regimen. J. Law Med. Ethic 2018, 46, 81-94. [CrossRef]

70. Cole, J.; Bickersteth, S. What's planetary about health? An analysis of topics covered in The Lancet Planetary Health 's first year. Lancet Planet. Health 2018, 2, e283-e284. [CrossRef] 